\title{
ESTRUTURA DA VEGETAÇÃO DE MANGUE ASSOCIADA AO GRADIENTE DE INUNDAÇÃO NO LITORAL NORTE DO ESPÍRITO SANTO, BRASIL ${ }^{1}$
}

\begin{abstract}
Vinícius Londe², Débora Mello Salles², Mariangela Garcia Praça Leite² e Yasmine Antonini²
RESUMO - O manguezal é um ecossistema de grande complexidade que ocorre na interface entre os ambientes marinhos e terrestres, mas que apresenta baixa riqueza de espécies vegetais adaptadas às suas condições diferenciadas. Avaliar a estrutura e distribuição da vegetação no manguezal do rio Piraquê-Açu, ES, associando-as com parâmetros abióticos ao longo de um gradiente, foi o objetivo deste estudo. Em seis parcelas de $100 \mathrm{~m}^{2}$ cada, foram registrados 306 indivíduos vivos e um morto, pertencentes às espécies Laguncularia racemosa, Rhizophora mangle, Avicennia schaueriana, Terminalia catappa e outras quatro indeterminadas, sendo L. racemosa de maior densidade, dominância, área basal e IVI. A altura média das árvores foi de 4,2 m (DP $\pm 1,9)$ e a CAP, de 12,4 cm (DP $\pm 9,5)$, estando a maioria dos indivíduos em classes de CAP até $10 \mathrm{~cm}$. O manguezal encontrava-se em estado juvenil e pouco desenvolvido estruturalmente, e houve distinção na distribuição das espécies na área, com espécies associadas ocorrendo na parcela mais elevada e menos úmida. As variáveis abióticas diferiram entre as parcelas, contudo apenas a umidade do substrato apresentou relação significativa com a abundância de indivíduos e circunferência dos troncos.
\end{abstract}

Palavras-chave: Fitossociologia; Manguezal; Umidade do solo.

\section{STRUCTURE OF THE MANGROVE VEGETATION ASSOCIATED TO FLOOD GRADIENT IN THE NORTH COASTAL ESPÍRITO SANTO, BRAZIL}

\begin{abstract}
The mangrove is an ecosystem of great complexity that occurs at the interface between the marine and terrestrial environments. Consequently, it has low richness of vegetables species, adapted to their different physical and chemical conditions. The objectives of this study were to assess the structure and distribution of vegetation in the mangrove river Piraquê-açu/ES, associated with abiotic parameters along a flooding gradient. Three hundred and six alive individuals and one dead were recorded in six $100 \mathrm{~m}^{2}$ plots. The plants belong to the following species: Laguncularia racemosa, Rhizophora mangle, Avicennia schaueriana, Terminalia catappa and four undetermined. L. racemosa was the species with the highest density, dominance, basal area and IVI. The average height of the trees was $4.2 \mathrm{~m}(S D \pm 1.9 \mathrm{~m})$ and CBH (circumference at breast height) was $12.4 \mathrm{~cm}$ (SD \pm 9.5 ), with the majority of individuals in $C B H$ class of $10 \mathrm{~cm}$. The mangrove forest studied is in juvenile stage, with minor structural development. A significant difference was found in the distribution of the species in the area, with associated species occurring in the plot on higher altitudes and lower soil water content. Although all abiotic variables differed among the plots, only substrate moisture showed significant relationship with the abundance of individuals and circumference of the trunks.
\end{abstract}

Keywords: Mangroves; Phytosociology; Soil moisture.

\footnotetext{
${ }^{1}$ Recebido em 24.01.2013 aceito para publicação em 06.08.2013.

${ }^{2}$ Programa de Pós-Graduação em Ecologia de Biomas Tropicais da Universidade Federal de Ouro Preto, UFOP, Brasil. E-mail: <vlonde.ecologia@gmail.com>,<dmsallesbr@yahoo.com.br>,<mgpleite@gmail.com>e <antonini.y@gmail.com>.
} 


\section{INTRODUÇÃO}

As florestas de mangue são ecossistemas abertos, de grande complexidade, onde acontecem significantes conexões entre o solo, o estuário, o oceano e o sistema atmosférico (CUNHA-LIGNON et al., 2009). Os mangues são ecossistemas que ocorrem na interface entre os ambientes marinhos e terrestres, tendo como principal característica a sua dependência das marés (SCHAEFFER-NOVELLI, 1995).

Os manguezais apresentam quatro compartimentos interdependentes, porém com características intrínsecas bastante individualizadas: água, solo, flora e fauna. Esses ecossistemas fundamentam a perfeita integração e o equilíbrio dinâmico entre os seus constituintes no contexto ambiental. Dessa maneira, não se devem fracionar os estudos relacionados a ele, pois a associação entre seus aspectos físicos e bióticos é tão harmoniosa que a valorização de um dos seus compartimentos mascara e desvia o entendimento da dinâmica ecológica desses ecossistemas (ALVES, 2002).

No manguezal, os fatores geradores de estresse ambiental se apresentam num gradiente, com o estresse aumentando com a distância da linha d’água e com os efeitos relacionados à inundação pelas marés (aumento da salinidade, variações granulométricas do substrato, intensidade de ondas e correntes), resultando em condições que podem prejudicar o desenvolvimento das plântulas (FRY et al., 2000). Esses e outros aspectos explicam a baixa riqueza de espécies vegetais registradas em manguezais, sendo no Brasil encontradas apenas seis espécies, das quais quatro são registradas no Estado do Espírito Santo (SILVA et al., 2005; ALMEIDA, 2007): Rhizophora mangle L.; Avicennia schaueriana Stapf. \& Leechm.; Avicennia germinans (L.) Learn.; e Laguncularia racemosa (L.) Gaetern. E, como associados, são encontrados os gêneros Spartina, Hibiscus e Acrostichum (SILVA et al., 2005).

A baixa diversidade vegetal do manguezal sugere fácil interpretação estrutural e funcional do ecossistema, porém ele é dotado de uma complexidade funcional enorme, dificultando a padronização de conceitos ecológicos sobre esse ambiente (DE ROSA et al., 2007). Assim, a caracterização estrutural da vegetação de um manguezal, associada aos aspectos físicos (topografia, granulometria, umidade do solo etc.), constitui valiosa ferramenta para o entendimento da evolução desse ecossistema diante das condições ambientais.
Apesar da importância dos manguezais serem universalmente reconhecida, a melhor forma de lidar com esses ecossistemas únicos é ainda um problema. Grande parte das zonas úmidas costeiras, que incluem os manguezais, vem sofrendo, em maior ou menor grau, pressões antrópicas, e alguns tipos de uso (ou abuso) incluem a destruição total de suas florestas (VANNUCCI, 2004). Aliado a isso, as transformações climáticas vêm pressionando esses ecossistemas, já que são extremamente dependentes das oscilações do nível do mar e dos influxos de água doce, ou seja, os manguezais estão entre os ecossistemas mais ameaçados do planeta (LIMAYE; KUMARAN, 2012).

Segundo Vannucci (2004), apesar de existir grande volume de dados sobre manguezais, apenas pequena parte destes está publicada em jornais científicos, o que dificulta sua preservação. Nesse contexto, os estudos da estrutura da vegetação dos manguezais permitem detectar as respostas desse ecossistema às variações ambientais, assim como a adoção de ações que contribuam para sua conservação (SOARES, 1999), também auxiliam na compreensão da complexidade funcional e fornecem ideia do grau de desenvolvimento da floresta de mangue. Além disso, pela correlação dos aspectos físicos com os bióticos é possível identificar e delimitar áreas heterogêneas, permitindo comparações entre seus compartimentos. Porém, para interpretação mais precisa do padrão de distribuição das espécies, já que são comuns a covariação e interação de fatores ao longo do gradiente de inundação, é recomendável a realização de estudos que incluam análises multifatoriais e experimentos controlados (BERNINI, 2008). Nesse sentido, este trabalho objetivou conhecer a estrutura e distribuição da vegetação de um trecho do manguezal do rio Piraquê-Açu, no litoral capixaba, associando-as com alguns parâmetros abióticos ao longo de um gradiente de inundação típico de manguezais tropicais.

\section{MATERIAL E MÉTODOS}

\section{1. Área de estudo}

Este trabalho foi realizado em setembro de 2011, num remanescente de manguezal situado à margem esquerda do estuário formado pelo encontro das águas do Piraquê-Açu e do Piraquê-Mirim, no Distrito de Santa Cruz, Município de Aracruz, no litoral Norte do Estado do Espírito Santo (Figura 1). Esse estuário é margeado 
por extenso manguezal, que ocupa uma área de 12 km², sendo caracterizado por sua rara beleza e rica biodiversidade (BARROSO, 2004).

De acordo com Schaeffer-Novelli et al. (1990), o litoral brasileiro pode ser dividido em oito segmentos fisiográficos. O estuário do rio Piraquê-Açu está incluído na porção central (Vitória) do segmento VI, o qual se estende desde o Recôncavo Baiano, BA (1300'S), até Cabo Frio, RJ (2300'S). A região é caracterizada por uma cadeia de montanhas que se aproxima da Costa, restringindo a largura da planície costeira.

\subsection{Metodologia}

Foi traçada uma linha de 115 m de comprimento, sendo $90 \mathrm{~m}$ paralelos ao rio e $25 \mathrm{~m}$ perpendiculares a ele, onde foram distribuídas seis parcelas não contíguas de $100 \mathrm{~m}^{2}$ (10 x $10 \mathrm{~m}$ cada, alocando-se duas na linha perpendicular (parcelas A e B) e quatro na linha paralela (parcelas C, D, E e F) (Figura 1). Segundo Pillar (2004), onde a variância ambiental é pequena, ou seja, existe homogeneidade ambiental (como nos manguezais), o número de unidades amostrais necessárias para atingir certa precisão da média pode ser reduzido.

De todos os indivíduos presentes nas parcelas foram medidos a CAP (circunferência à altura do peito, $1,30 \mathrm{~m}$ ), utilizando-se fita métrica, e a altura estimada

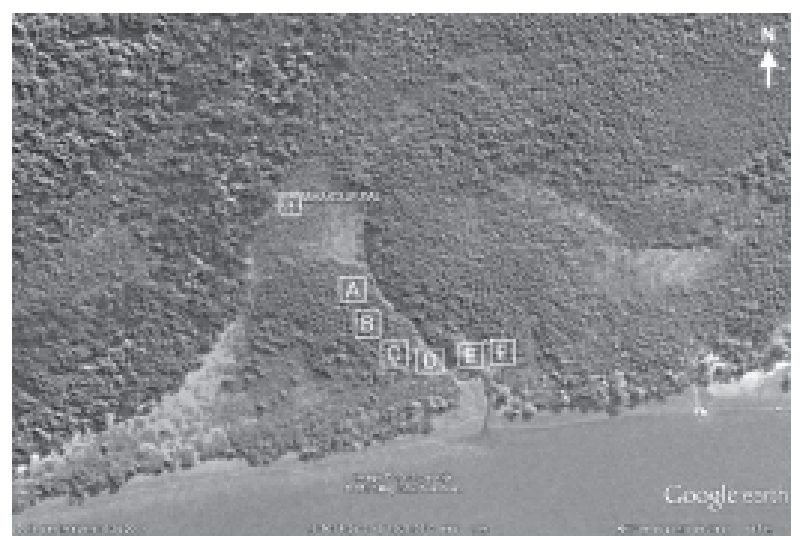

Figura 1 - Mapa da área de estudo no estuário do rio PiraquêAçu, Aracruz, ES, com os pontos de locação das parcelas amostrais. Entre as coordenadas 1956’56.72"S; 4009’28.91"O e 1956’58.52"S; 4009'21.68"O.

Figure 1 - Study area maps in the estuary of the river Piraquêaçu, Aracruz, ES, with the allocation sites of the sample plots. Between coordinates: 1956'56.72"S; 4009'28.91"W and 19'56'58.52"S; 4009'21.68"W. com o auxílio de réguas de madeira. Optou-se por não definir uma circunferência mínima para medição da CAP, já que critérios menos restritivos incluirão maior número de indivíduos e têm maior probabilidade de incluir mais espécies (MORO; MARTINS, 2011). Os indivíduos foram marcados com fita adesiva e pincel de tinta permanente para evitar a recontagem.

Foram utilizados os seguintes parâmetros na análise fitossociológica: abundância, densidade, dominância, frequência, área basal e índice de valor de importância (IVI). Os dados foram tratados em planilha própria para fitossociologia no programa Microsoft Excel Versão 2010.

Para caracterização do perfil topográfico, foram feitas medições, no período de maré baixa e maré cheia, da distância da linha em relação à lâmina d’água. Também foram coletadas, aleatoriamente, três amostras de solo até a profundidade de $15 \mathrm{~cm}$, em cada parcela. As amostras foram acondicionadas em sacos plásticos, etiquetadas e encaminhadas ao Laboratório do Instituto EcoMares (Nova Almeida, ES), para análise dos parâmetros umidade, granulometria, infiltração e permeabilidade.

Para estimar a umidade do solo, as amostras foram pesadas em balança de precisão ainda úmidas e depois de secas em estufa a $100{ }^{\circ} \mathrm{C}$, durante $4 \mathrm{~h}$, foram pesadas novamente. A granulometria foi obtida pelo método de peneiramento a seco, que consiste em utilizar um conjunto de peneiras com telas de malhas de $2 \mathrm{~mm}$ a 0,063 mm colocadas em um agitador mecânico durante cinco minutos. A escala granulométrica utilizada foi a de Wentworth (1922), em que as frações maiores que 0,063 mm são classificadas como areias/grânulos e as menores, como silte/argila (SUGUIO, 1973).

Nos testes de infiltração e permeabilidade, as três porções de solo foram misturadas compondo uma única amostra por parcela. O material foi depositado em recipientes plásticos transparentes de 15 cm de diâmetro com cinco perfurações na base e colocados, cada um, dentro de um béquer. Despejaram-se 100 mL de uma solução de água e corante artificial amarelo em cada recipiente, e cronometrou-se o tempo gasto para que a solução infiltrasse totalmente na amostra. O volume de solução que passou pela amostra e ficou armazenado no béquer também foi medido.

Foi empregada a estatística descritiva na análise das variáveis estruturais (altura, CAP e área basal) e físicas (umidade do solo, concentração de silte/argila

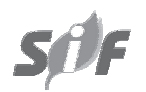

Revista Árvore, Viçosa-MG, v.37, n.4, p.629-637, 2013 
e areia). Para verificar se havia diferenças significativas $(\mathrm{p}<0,05)$ na estrutura da vegetação, usou-se KruskalWallis e nos parâmetros físicos, Análises de Variância (ANOVA one-way) na área, além do teste de correlação de Pearson entre abundância x umidade, silte/argila e areia, sendo também realizada a Regressão Linear Múltipla entre os parâmetros estruturais e físicos. Os testes foram executados com os softwares PAST versão 2.16. e MINITAB versão 16.1 .

\section{RESULTADOS}

\subsection{Geral}

Foram registradas oito espécies arbóreas na área, entre elas três típicas de manguezal: Rhizophora mangle L., Avicennia schaueriana Stapf \& Leechm. ex Moldenke e Laguncularia racemosa (L.) C.F. Gaertn.; e cinco típicas de terra firme, mas, devido à ausência de material fértil, apenas a Terminalia catappa L. foi identificada até espécie. Esta é considerada exótica no Brasil, sendo originária da Ásia e Madagascar (LORENZI et al., 2003).

Foram amostrados 306 indivíduos vivos e um morto, constituindo a Laguncularia racemosa a espécie mais abundante, com 183 indivíduos (60\% do total), seguida da Rhizophora mangle, com 92 espécimes (30\%), Avicennia schaueriana com 21 plantas (7\%) e, por fim, 10 indivíduos distribuídos entre as demais espécies de terra firme, equivalendo a 3\% do total.

Quanto à estrutura arbórea, a altura média registrada foi de 4,2 m e a CAP média, 12,4 cm. A espécie de maior densidade relativa foi a Laguncularia racemosa (59,8\%), seguida da Rhizophora mangle (30,1\%), e as demais espécies correspondentes a 10,1\% do total. A L racemosa foi também a espécie dominante na área (61,7\%), seguida da $R$. mangle (16,3\%), Avicennia schaueriana (11,5\%), e as demais espécies juntas tiveram 10,5\% de dominância. Com relação à frequência relativa, tanto a A. schaueriana quanto a $L$. racemosa tiveram $26,2 \%$, a $R$. mangle $21,1 \%$ e as demais espécies representaram 26,5\% do total (Tabela 1).

Com relação à área basal, a espécie mais representativa foi a Laguncularia racemosa com 62\%, seguida da Rhizophora mangle com 16\% e da Avicennia schaueriana com 11\%. Essas três espécies também se destacaram no IVI, porém com substancial relevância para $L$. racemosa, enquanto as espécies de terra firme tiveram o menor IVI e, também, menor importância fitossociológica (Tabela 1). Verificaram-se diferenças significativas $(\mathrm{p}<0,05)$ entre os parâmetros altura, CAP e área basal na área.

Evidenciou-se que a floresta de mangue se encontrava pouco desenvolvida estruturalmente, pois foi registrado grande número de indivíduos dispostos nas classes de CAP de 1 a $10 \mathrm{~cm}$ e poucas plantas com CAP igual ou superior a $30 \mathrm{~cm}$ (Figura 2).

A média de todas as amostras de substrato coletadas na área relevou que $66 \%$ do material consistia de solo e 34\% de água, e na análise granulométrica verificou-se que $96 \%$ do material pertencia à fração areia e apenas $4 \%$ era caracterizado como silte/argila (Tabela 2). Houve diferença significativa $(\mathrm{p}<0,01)$ entre os parâmetros solo, umidade e silte/argila na área de estudo.

\subsection{Parcelas}

Pelo perfil topográfico, pode-se perceber que as parcelas A e B (interioranas) são pouco influenciadas pela maré alta, enquanto as parcelas $\mathrm{C}$ e D, próximas ao rio, ficam completamente submersas durante parte do dia. A parcela E é a mais elevada entre as seis, chegando a 1,20 m de altura, e tem menos influência das marés, acompanhadas da parcela F (Figura 3). Enquanto a parcela E apresentou maior riqueza, com cinco espécies, na A foi encontrada apenas a Laguncularia racemosa. Notou-se essa espécie abundante nas parcelas B $(\mathrm{n}=82), \mathrm{C}(\mathrm{n}=48)$ e A $(\mathrm{n}=30)$, decrescendo nas parcelas $\mathrm{D}(\mathrm{n}=12)$ e $\mathrm{F}(\mathrm{n}=11)$, e nenhum indivíduo foi registrado na parcela E. A Rhizophora mangle foi abundante nas parcelas D $(n=54)$ e C $(n=23)$ e ausente nas A e E. No geral foram registrados poucos indivíduos de Avicennia schaueriana na área, os quais estavam distribuídos nas parcelas B $(n=4), C(n=3), D(n=8)$, E $(n=4)$ e $F(n=2)$.

As árvores mais altas e com maior CAP ocuparam a parcela E (mais elevada e seca) e as mais baixas, a parcela A. Com relação à área basal, a maior média também foi obtida na parcela E e a menor, na A (composta apenas pela $L$. racemosa). Já para densidade absoluta houve inversão, sendo o maior valor registrado na parcela A e o menor, na E.

A parcela D apresentou elevada umidade no solo (cerca de 50\%), enquanto a parcela $\mathrm{E}$ foi a menos úmida, com apenas 3,8\% de água, e teve o solo mais arenoso, sendo constituído basicamente da fração areia (partículas $>0,063 \mathrm{~mm}$ ), enquanto a parcela B teve mais silte/argila nas amostras $(<0,063 \mathrm{~mm})$ (Tabela 2$)$. 
Tabela 1 - Valores obtidos na análise fitossociológica do manguezal do rio Piraquê-Açu, ES.

Table 1 - Results of the phytosociological analysis in the mangrove of the river Piraquê-Açu, ES.

\begin{tabular}{|c|c|c|c|c|c|c|c|c|c|c|}
\hline \multirow[b]{2}{*}{ Espécie } & \multicolumn{2}{|c|}{ Densidade } & \multicolumn{2}{|c|}{ Dominância } & \multicolumn{2}{|c|}{ Frequência } & \multicolumn{2}{|c|}{ Área Basal } & \multicolumn{2}{|c|}{ IVI } \\
\hline & $\begin{array}{l}\text { Absoluta } \\
\text { (ind./ha) }\end{array}$ & $\begin{array}{c}\text { Relativa } \\
\text { (\%) }\end{array}$ & $\begin{array}{l}\text { Absoluta } \\
(\mathrm{AB} / \mathrm{ha})\end{array}$ & $\begin{array}{c}\text { Relativa } \\
(\%)\end{array}$ & Absoluta & $\begin{array}{c}\text { Relativa } \\
(\%)\end{array}$ & $\left(\mathrm{m}^{2} \cdot \mathrm{ha}^{-1}\right)$ & $(\%)$ & & (\%) \\
\hline A. schaueriana & 350 & 6,9 & 11335 & 11,5 & 83,3 & 26,2 & 680 & 11 & 44,7 & 14,9 \\
\hline L. racemosa & 3050 & 59,8 & 60989 & 61,7 & 83,3 & 26,2 & 3659 & 62 & 147,9 & 49,3 \\
\hline R. mangle & 1533,3 & 30,1 & 16054 & 16,3 & 66,7 & 21,1 & 963 & 16 & 67,4 & 22,5 \\
\hline T. catappa & 50 & 1,0 & 4050 & 4,1 & 16,7 & 5,3 & 243 & 4 & 10,3 & 3,4 \\
\hline Indet. 01 & 66,7 & 1,3 & 5646 & 5,7 & 16,7 & 5,3 & 339 & 6 & 12,3 & 4,1 \\
\hline Indet. 02 & 16,7 & 0,3 & 531 & 0,5 & 16,7 & 5,3 & 32 & 1 & 6,1 & 2 \\
\hline Indet. 03 & 16,7 & 0,3 & 33 & 0,1 & 16,7 & 5,3 & 2 & 0 & 5,6 & 1,9 \\
\hline Indet. 04 & 16,7 & 0,3 & 133 & 0,1 & 16,7 & 5,3 & 8 & 0 & 5,7 & 1,9 \\
\hline
\end{tabular}

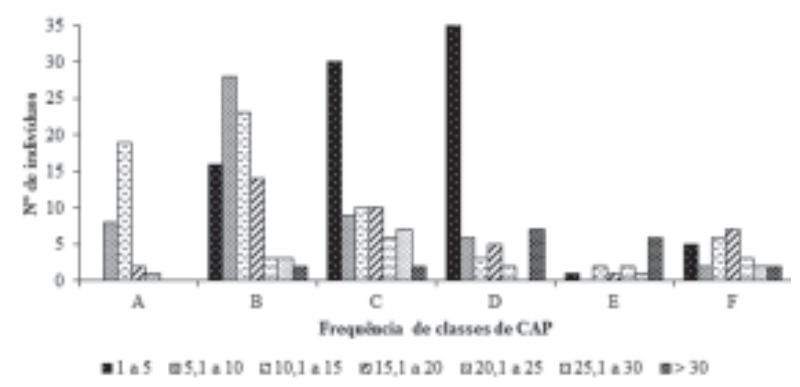

Figura 2 - Número de indivíduos distribuídos em classes de CAP nas parcelas no estuário do rio Piraquê-Açu, Aracruz, ES.

Figure 2 - Number of individuals distributed in classes of CHB in the plots of the estuary of river PiraquêAçu, Aracruz, ES.

Tanto a estrutura da vegetação (altura, CAP e área basal) quanto os parâmetros físicos do substrato (\% umidade, frações silte/argila e areia) variaram significativamente entre as parcelas amostrais $(\mathrm{p}<0,01)$, revelando a heterogeneidade biótica e abiótica da área. Já a regressão linear múltipla mostrou haver relação significativa somente entre a porcentagem de umidade do solo e a CAP $(p<0,01)$, sendo esta uma relação inversa, ou seja, à medida que o teor de água aumentou, a CAP diminuiu.

O número de indivíduos nas parcelas correlacionou-se com a umidade do solo (Pearson $=0,8 ; \mathrm{p}=0,02$ ), e a abundância aumentou com o acréscimo da umidade, e o mesmo padrão foi verificado entre abundância e teor silte/argila (Pearson =0,92; $<<0,01$ ). Entre o número de indivíduos e areias houve correlação inversa, sendo encontrada maior abundância onde havia menos concentração de areias (Pearson $=-0,92 ; \mathrm{p}<0,01)$.
Notou-se que na parcela $\mathrm{E}$, menos úmida, houve somente a espécie Avicennia schaueriana como típica de mangue, com apenas quatro indivíduos e outras seis árvores das espécies associadas, enquanto na parcela mais úmida (D) ocorreram as três espécies de mangue, constituindo a Rhizophora mangle na mais abundante.

A maior diferença no tempo de infiltração ocorreu entre as parcelas D e F, sendo na primeira gasto maior tempo para que o líquido transpassasse a amostra (17 min $50 \mathrm{seg}$ ) e na segunda, o menor tempo (1 min 46 seg). A permeabilidade também foi variável, sendo a parcela E a mais permeável, com $17 \mathrm{~mL}$, enquanto nas parcelas $\mathrm{B}$ e $\mathrm{C}$ nenhum volume de água foi detectado até o término do experimento.

\section{DISCUSSÃO}

Laguncularia racemosa foi a espécie de maior densidade, frequência e dominância na área, sendo esta última associada às florestas menos desenvolvidas estruturalmente e em vias de recomposição (BERNINI; REZENDE, 2004). Em outros trabalhos, essa espécie apresentou padrão semelhante, como aqueles observados nos manguezais dos estuários dos rios Itapoana, ES-RJ (BERNINI; REZENDE, 2010); Reis Magos, ES (TEIXEIRA et al., 2009); Paraíba do Sul, RJ (BERNINI; REZENDE, 2004); e São Mateus, ES (SILVA et al., 2005). Todavia, é importante ressaltar que a espécie dominante pode variar de manguezal para manguezal, em virtude das características abióticas e bióticas (ex.: tolerância à inundação e à salinidade, competição interespecífica), além da influência do estresse natural e antrópico (PETRI et al., 2011). No manguezal estudado, o que pode estar influenciando 
Tabela 2 - Percentual dos parâmetros físicos analisados nas parcelas amostrais no manguezal do rio Piraquê-Açu, ES (média \pm desvio-padrão).

Table 2 - Percentage of the physical parameters analyzed in the plots in the mangrove river Piraquê-açu, ES (average \pm standard deviation).

\begin{tabular}{lcccc}
\hline Parcela & Solo & Água & Areia & Silte/Argila \\
\hline A $(n=3)$ & $67,72 \pm 7,63$ & $32,28 \pm 7,63$ & $97,15 \pm 2,84$ & $2,85 \pm 2,84$ \\
B $(n=3)$ & $54,47 \pm 6,61$ & $45,53 \pm 6,61$ & $91,46 \pm 1,28$ & $8,54 \pm 1,28$ \\
C $(n=3)$ & $57,68 \pm 4,43$ & $42,32 \pm 4,43$ & $96,12 \pm 0,30$ & $3,88 \pm 0,30$ \\
D $(n=3)$ & $49,78 \pm 4,51$ & $50,22 \pm 4,51$ & $92,95 \pm 4,55$ & $7,05 \pm 4,55$ \\
E $(n=3)$ & $96,17 \pm 2,87$ & $3,83 \pm 2,87$ & $99,71 \pm 0,16$ & $0,29 \pm 0,16$ \\
F $(n=3)$ & $71,65 \pm 1,55$ & $28,35 \pm 1,55$ & $98,72 \pm 0,63$ & $1,28 \pm 0,63$ \\
\hline
\end{tabular}

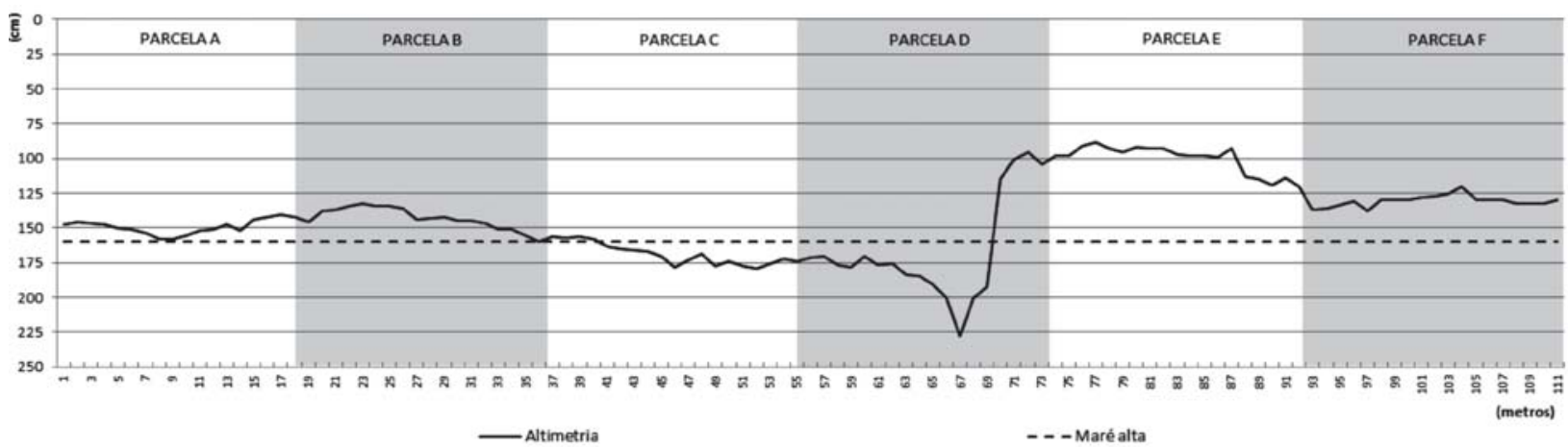

Figura 3 - Caracterização topográfica das seis parcelas amostrais no estuário do rio Piraquê-Açu, Aracruz, ES.

Figure 3 - Topographic profile of the six plots in the estuary of the river Piraquê-Açu, Aracruz, ES.

na dominância da Laguncularia racemosa é a topografia do terreno, o menor período em que o substrato permanece encharcado durante a maré alta, já que apenas as parcelas C e D ficaram completamente inundadas (Figura 3); a salinidade não foi medida.

Comparando esse manguezal com o do rio Reis Magos (TEIXEIRA et al., 2009), estuário mais próximo, e considerando as médias de altura e CAP, podese concluir que a floresta deste estudo se encontrava menos desenvolvida estruturalmente. Esse manguezal, apesar de protegido por lei, pode ter sido antropizado anteriormente e, agora, se encontra em fase de regeneração. De fato, observaram-se sinais de corte de indivíduos e de ocupação humana em porções da floresta. Somados aos fatores citados, a baixa altura das árvores, a elevada densidade, a abundância de indivíduos em classes inferiores de CAP e o fato de somente ter sido registrado um indivíduo morto corroboram a inferência de que esse sistema se encontra em estágio juvenil de desenvolvimento. Durante seu amadurecimento, as florestas de manguezais passam de uma fase em que a área é ocupada por alta densidade de árvores de diâmetro reduzido para uma fase madura, em que dominam poucas árvores de grande porte e volume (CINTRÓN, 1987).

Laguncularia racemosa também exibiu maior importância social na comunidade, com IVI de 49,3\%, corroborando estudo fitossociológico realizado no manguezal de Saubara (BA), em que essa espécie também se destacou, apresentando IVI elevado de 96,8\% (PARAGUASSU; SILVA, 2007).

A evidência de maior riqueza de espécies na parcela e pode ser em função do seu nível topográfico mais elevado, ao solo arenoso, mais permeável e baixa taxa de saturação hídrica. Esses fatores parecem estar favorecendo o desenvolvimento de espécies “alóctones”, enquanto restringem as de mangue. A presença de espécies alóctones (associadas) é um indicativo da presença de água doce no subsolo, necessária à sua manutenção (BERNINI; REZENDE, 2010). 
De acordo com Bernini et al. (2006), no substrato do manguezal as concentrações de nutrientes variam ao longo da zona intertidal, e a absorção de determinados cátions depende da salinidade. Assim, a relação inversa entre a elevação da umidade do solo e o decréscimo da CAP pode estar associada ao excesso de água. Essa relação provoca um gasto energético maior das plantas para alcançar o equilíbrio hídrico, a produção de compostos desintoxicantes e a eliminação do excedente de sais que, por sua vez, diminuem a absorção de nutrientes minerais e reduzem a taxa de crescimento e a produção de biomassa (LARCHER, 2000).

Os manguezais são ambientes altamente especializados, e as espécies de mangue que os ocupam apresentam notáveis adaptações às condições limitantes do meio intertidal (PROST; RABELO, 1996), como as glândulas secretoras de sais que os eliminam ativamente, acomodando-os nas folhas dentro de certos limites, por exemplo no gênero Avicennia (LARCHER, 2000). Talvez não exista outro grupo de plantas com tamanhas adaptações morfofisiológicas em condições extremas, como as espécies de mangue (KATHIRESAN; BINGHAM, 2001). Logo, a correlação entre a elevação da umidade do solo com o aumento no número de indivíduos das espécies de mangue, em especial Laguncularia racemosa, pode ser explicada, pois essas espécies são adaptadas a colonizar ambientes inundáveis e salinos.

A relação entre o aumento do número de indivíduos nas parcelas silte/argilosas e o consequente decréscimo nas parcelas arenosas pode ser explicada com base nas propriedades físico-químicas do substrato. As partículas de solo têm cargas negativas em sua superfície, e solos com partículas menores, como as argilas, possuem maior proporção de área superficial por volume e expõem mais cargas, gerando maior capacidade de carga catiônica de nutrientes minerais com as raízes das plantas (TAIZ; ZEIGER, 1998).

Verificou-se que a parcela de substrato mais seco (E) apresentou o maior valor de área basal devido à presença das espécies de terra firme que tiveram diâmetros de troncos bastante superiores aos das espécies de mangue. Nas demais parcelas, onde apenas ocorreram as espécies de mangue, a área basal variou de 13 a $25 \mathrm{~m}^{2} \mathrm{ha}^{-1}$, com o teor de água sempre superior a $25 \%$.

A composição florística variou entre as parcelas, o que pode estar associado às características físicas distintas entre elas, tal como o teor de umidade, granulometria e salinidade. O regime hídrico e o substrato são importantes fatores que controlam a zonação das espécies de mangue, e cada espécie tem amplitude de tolerância a esses fatores (THOM, 1967 apud BERNINI, 2008).

Observou-se gradiente na disposição de espécies na área, estando Laguncularia racemosa abundante nas parcelas interioranas (A, B); Rhizophora mangle, mais abundante na parcela $\mathrm{D}$, que tem maior influência das marés; e Avicennia schaueriana, pouco abundante na área, mas habitando a parcela mais alta, menos úmida e mais arenosa, juntamente com espécies atípicas de manguezal. Esses resultados corroboram os obtidos por Jesus et al. (2009) na região. De acordo com esses autores, a floresta do manguezal é composta basicamente por três espécies arbóreas, sendo elas: $R$. mangle, encontrada apenas nas margens formando uma franja estreita; $L$. racemosa, geralmente encontrada em solos mais rasos; e A. schaueriana, mais comum em solos mais firmes e arenosos.

\section{CONCLUSÃO}

Diversos fatores bióticos e abióticos interagem e variam de um local para outro, afetando a distribuição espacial distinta das espécies, pois cada uma responde diferentemente às variáveis (JIMÉNEZ; SAUTER, 1991), não existindo explicação geral aplicável a todas as florestas de mangue (BERNINI, 2008). Esse fato foi verificado neste estudo, pois entre as variáveis analisadas apenas a umidade do substrato apresentou relação significativa com a abundância de indivíduos e com a circunferência dos troncos, mas não explicou os demais parâmetros estruturais.

\section{AGRADECIMENTOS}

À CAPES, pela concessão da bolsa ao mestrando Vinícius Londe; à FAPEMIG, pela bolsa de mestrado de Débora Salles; ao CNPq, pelas bolsas de pesquisa de Yasmine Antonini e Mariângela Leite; e à PROPP e ao PPG Ecologia de Biomas Tropicais da UFOP, pelo auxílio financeiro.

\section{REFERÊNCIAS}

ALMEIDA, R. Conservação dos manguezais capixabas e sua importância para a diversidade biológica. In: MENEZES, L. F. T.; PIRES, F. R.; PEREIRA, O. J. (Org.) Ecossistemas Costeiros do Espírito Santo: conservação e preservação. Vitória: EDUFES, 2007.p.103-115.

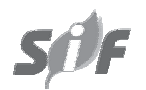

Revista Árvore, Viçosa-MG, v.37, n.4, p.629-637, 2013 
ALVES, T. C. A. Caracterização geoquímica do substrato lamoso de zonas de manguezal da Baía de Aratu - Bahia. 2002. 111f. Dissertação (Mestrado em Geoquímica e Meio Ambiente) - Universidade Federal da Bahia, Salvador, 2002.

BARRoso, G. F. Development of an evaluation framework for sustainable bivalve aquaculture: a strategic plan approach in Espírito Santo, Brazil. 2004. $229 f$. Unpublished PhD Thesis (Geography) - University of Victoria, Canada, 2004.

BERNINI, E. et al. Composição química do sedimento e de folhas das espécies do manguezal do estuário do Rio São Mateus, Espirito Santo, Brasil. Revista Brasileira de Botânica, v.29 n.4, p.689-699, 2006.

BERNINI, E.; REZENDE, C. E. Estrutura da vegetação em florestas de mangue do estuário do rio Paraíba do Sul, Estado do Rio de Janeiro, Brasil. Acta Botânica Brasílica, v. 18, n. 3, p. 491-502, 2004.

BERNINI, E.; REZENDE, C. E. Variação Estrutural em florestas de mangue do estuário do rio Itabapoana, ES-RJ. Biotemas, v. 23, n. 1, p. 4960, 2010.

BERNINI, E. Estrutura da cobertura vegetal e produção de serapilheira da floresta de mangue do estuário do rio Paraíba do Sul, Estado do Rio de Janeiro, Brasil. 2008. 150f. Tese (Doutorado em Ecologia e Recursos Naturais) - Universidade Estadual do Norte Fluminense, Campos dos Goytacazes, 2008.

CINTRÓN, G. Caracterización y manejo de áreas del mangle. In: SIMPÓSIO SOBRE

ECOSSISTEMAS DA COSTA SUL E SUDESTE

BRASILEIRA: Síntese dos conhecimentos, Cananeia. Anais... São Paulo: Academia de Ciência do Estado de São Paulo, v. 3, 77-75, 1987.

CUNHA-LIGNON, M. et al. Analysis of mangrove forest succession, using sediment cores: a case study in the Cananeia - Iguape coastal system, São Paulo-Brazil. Brazilian Journal of Oceanography, v. 57, n. 3, p. 161-174, 2009.
FRY, B. et al. Studies of nitrogen use by the red mangrove, Rhizophora mangle L. in South Florida. Estuarine, Coastal and Shelf Science, v. 50, p. 291-296, 2000.

JESUS, H. C. et al. Avaliação da poluição ambiental dos rios Piraquê-açu e Piraquê-mirim (Santa Cruz - ES) através da análise de águas, biomonitores e sedimentos. Relatório Técnico- Projeto Aracruz Celulose, Processo UFES n 034373/2007-80. 2009.

JIMÉNEZ, J. A.; SAUTER, K. Structure and dynamics of mangrove forests along a flooding gradient. Estuaries, v. 14, n. 1, p. 49-56, 1991.

KATHIRESAN, K.; BINGHAM, B. L. Biology of mangroves and mangrove ecosystems.

Advances in Marine Biology, v. 40, p. 81-251, 2001.

LARCHER, W. Ecofisiologia vegetal. In: PRADO, C. H. B. A. (Trad.). São Carlos: Rima Artes e Textos, 2000. 531 p.

LIMAYE, R. B.; KUMARAN, K. P. N. Mangrove vegetation responses to Holocene climate change along Konkan coast of south-western India, Quaternary International, v.263, n.14, p.114-128, 2012.

LORENZI, H. et al. Árvores exóticas no

Brasil: madeireiras, ornamentais e aromáticas. Nova Odessa: Instituto Plantarum, 2003. 384p.

MORO, M. F.; MARTINS, F. R. Métodos de levantamento do componente arbóreo-arbustivo. In: FELFILI, J. M. et al. (Ed.) Fitossociologia no Brasil: métodos e estudos de casos. Viçosa, MG: Universidade Federal de Viçosa, 2011. p.174-212.

PARAGUASSU, L. A. A.; SILVA, M. N. Caracterização fitossiológica do manguezal de Porto de Sauipe, Entre Rios, Bahia. Diálogo \& Ciência: Revista da Rede de Ensino FTC. v. 5, n. 12, p.1-12, 2007

PETRI, D. J. C. et al. Distribuição das espécies e estrutura do manguezal do Rio Benevente, Anchieta, ES. Biota Neotropica, v. 11, n. 3, p. 107-116, 2011. 
PILLAR, V. D. Suficiência amostral. In: BICUDO, C. E. M.; BICUDO, D. C. (Eds.). Amostragem em Limnologia. São Carlos: Rima, 2004.

PROST, M. T. R. C.; RABELO, B. V. Variabilidade fitoespacial de manguezais litorâneos e dinâmica costeira: exemplos da Guiana Francesa, Amapá e Pará. Boletim do Museu. Paranaense Emílio Goeldi. Série Ciências da Terra, v. 8, p. 101-121, 1996.

SCHAEFFER-NOVELLI, Y. et al. Variability of mangrove ecosystems along the Brazilian coast. Estuaries, v. 13, n. 2, p. 204-218, 1990.

\section{SCHAEFFER-NOVELLI, Y. Manguezal:} ecossistema entre terra e mar. São Paulo, Caribean Ecological Research, 1995. 64 p.

SILVA, M. A. B.; BERNINI, E.; CARMO, T. M. S. Características estruturais de bosques de mangue do estuário do rio São Mateus, ES, Brasil. Acta Botânica Brasílica, v. 19, n. 3, p. 465-471, 2005.

SOARES, M. L. G. Estrutura vegetal e grau de perturbação dos manguezais da Lagoa da Tijuca, Rio de Janeiro, RJ, Brasil. Revista Brasileira de Biologia, v. 59, n. 3, p. 503-515, 1999.
SUGUIO, K. Introdução à sedimentologia. São Paulo: Edgard Blüncher, EDUSP, 1973. 318p.

TAIZ, L.; ZEIGER, E. Plant physiology. 2.ed. Sunderland: Sinauer, 1998. 792p.

TEIXEIRA, P. L. S. et al. Avaliação da estrutura da vegetação de um trecho do manguezal do rio Reis Magos, município de Fundão (ES). In: CONGRESSO DE ECOLOGIA DO BRASIL, 9. Anais... São Lourenço: 2009. p.1-3.

TOGNELLA, M. M. P. R. et al. Abordagens ecológicas em manguezal. In: MENEZES, L.F. T.; PIRES, F. R.; PEREIRA, O. J. (Org.) Ecossistemas Costeiros do Espírito Santo conservação e preservação. Vitória: EDUFES, 2007. p.103-115.

VANNUCCI, M. Mangrove management and conservation: present and future. New York: United Nations University Press, 2004. 324p.

WENTWORTH, C. K. A scale of grade and class terms for clastic sediments. Journal of Geology, v. 30, p. 377-392, 1922. 
